\title{
REALITAT I RACIONALITAT KIERKEGAARDIANES: LA CURVATURA ĖTICA DE LA SUBJECTIVITAT
}

Begonya Sáez

Arreu de l'obra pseudònima publicada per Soren Kierkegaard abans i fins al $1850 \mathrm{i}$ també en algun dels textos que apareixen al Diari del 1847, es fa perfectament plausible la tendencia pragmàtico-normativa que impregna el tractament de conceptes clàssics en l'àmbit del pensament, com ho són el concepte de realitat i de raó o reflexió.

D'una banda, la terminologia amb què es fa referència al real sembla patir els excessos de frivolitat 0 , en el pitjor dels casos, la manca de cura dels pseudònims kierkeggardians, els quals, ara s'hi remeten mitjançant el terme germànic "Virkelighed", ara mitjançant el terme llati "Realitet". D'altra banda, Kierkegaard s'embolica molt breument en un peculiar text dels seus diaris amb un concepte clau a la Postill la de Johannes Climacus, és a saber, la "doble reflexió": i ho fa des d'una posició fonamentalment teoritzant que sembla no superar els marges de la mera retòrica.

Una lectura més acurada d'aquests textos, però, condueix a la reflexió que els pseudònims i el mateix kierkegaard duen a terme al voltant de la significació de l'ètic en l'àmbit de la subjectivitat, tant en termes de realitat èsica com de racionalitat o reflexió ètiques. Aixi, aquella dicotomia aparentment causal i terminològica amb què s'esmenta el real, descobreix una dicotomia categorial segons la qual caldrà establir una distinció valorativa i normativa entre el real entès com a mön, o sia, com a marc ontològic comú a tots els subjectes, i el real entès com a exigència d'autorrealització en el món, és a dir, com a marc ètic comú a tots els subjectes. Aquesta serà la concepció que permetrà la reconstrucció de la realital ètica de tot $\mathbf{i}$ cada subjecte, que passa per la seva intel-lecio, pel seu coneixement teòric, diguem-ne, aixi com per la seva actualizació i/o apropiació. Aixi, l'existència deixa de ser un mer fet per esdevenir tasca; la realitat, afirmarà Kierkegaard a la seva tesi de magister, Sobre el Concepte d'Tronia, puix que ha de ser aprehesa alhora com a "regal" (Gave) i com a "tasea" (Opgave) (1.288).' es a dir, com a fet $i$ com a què fer 0 , si romanem en la terminologia especulativa, com a necessitat $i$ com a possibilitat: és la curvatura ètica de la subjectivitat, en què el "què puc saber" i el "què he de fer" kantians s'informen $i$ es condicionen mutuament i fermament.

La realitat deixa de ser una natura morta a l'abast del nostre esguard impassible i cientific i esdevé seu d'una relació de què n'és subjecte i objecte alhora tot individu, puix que en ella $f a$ realitat (virkeliggor) aquell conjunt de dades que el determinen com qui és: la seva biografia, el seu context socio-cultural i moral, etc... o sia, es fa realitat a si mateix. Pel que fa al cas, escriu encara Climacus en una línia força cartesiana a la Postil la, que

L'ünica realitat de qué que existeix ls més o meny's coneixement és lo seva própia realitat, el fet que existeir ${ }^{2} \mathrm{i}$ aquesta realitat és el seu únic interès (...) l'ünica realitat que hi ha per aquell qui existeix és la seva pròpia (realitat) ètica. $(10,22)$

1 La paginació indicada remet a la tercera edició danesa en vint volums de l'obra original de Soren Kier. kegaard; Samlede laerker, Gyldendal. Kobenhavn 1962-1964 i consigna el volum i la plana. Aixi, (1.238) n'indica el primer volum i la plana 288.

2 El subratllat és méu a ti de ressaltar la corncidència, si unés no formal, amb la formulació cartesiana tean coneguda per Kierkegaard, cogito ergo smm. Tambes Descartes sembla tenir "coneixunent" que existeix, encara que no es coneix: coneix o, millor dit, sap que es, peró no coneix o sap qui is. Aixi ho alima amb alguna reserva a la segona meditació: "ara sé amb cenesa que sóc, però encara no sé amb claredat qui sóc" pl. 24 a . Weditacions trad. al castellà de Vidal Pena, Alfaguara, Madrid, 1.977. 
La consistència ontològica de la realitat sembla dependre, per tant, del fet que l'individu se'n faci càrrec, que esdevingui "la seva pròpia (realitat) ètica". La tasca d'actualització de la subjectivitat passa, efectivament, per ила apropiació de la realitat. Altrament dit, només quan l'individu esdevé propietari responsable $i$ únic de la seva existència, és possible afirmar que ésser auto-conscient significa també "comprendre's a si mateix en l'existència" (10,52). La reflexió deixa de ser un estri per al raonament objectiu, per a l'esguard científic, i esdevé alló que el pseudònim kierkegaardià Anti-Climacus anomena a La malaltia per a la mort "auto-reflexió" o "reflexió ètica" $(15,111)$. Aixi, la racionalitat pren un gir pragmàtic $i$ configura la curvatura des d'on s'articula èticament la subjectivitat; es tracta del moment de la cloble reflexió.

La doble reflexio dessigna, aixi, el vaivé de la subjectivitat en què aquesta traça la corba des d'on se sostè èticament, des d'on es posseix com a projecte, enlairada per damunt de les possibilitats de las seva existència, per instal-lar-s'hi, però, repetidament. L'individu descobreix la realitat com a "idealitat ètica" $(10,24) \mathrm{i}$, respecte d'allò que observa es pregunta “és real (virkeligt)". I, immediatament "és possible?" "puc fer-ho jo també?". Aixi el subjecte ètic es pregunta per la seva pròpia realitat i formula així la "pregunta ètica", normativo-pragmàtica, que tot individu ha de fer-se a si mateix.

Aquesta concepció del realemt i del rationalem, no solament permet una lectura de l'obra pseudònima de Kierkegaard en clara oposició a Hegel, com és sabut. sinó també en oposició a Descartes. De fet, el projecte filosòfic kierkegaardià s'insereix en l'àmbit filosòfic amb l'objectiu primordial de reconciliar els dos àmbits que, segons Kicrkegaard, cspecialement el hegelianisme ha escindit: els àmbits del pensar (llegiu "pensar filosòfic") i de l'existència. A tall de conclusió convé concretar, mitjançant els conceptes suara tractats, fins a quin punt Kierkegaard pot ser també llegit com a oponent de Descartes.

(1) Hem vist com la realitat és concebuda per Kierkegaard de manera dual i, encara ınés, de manera dialèctica. La realitat és coneguda en tant que és actualitzada. Com vèiem, l'allunyament objectivant de la realitat hi porta implicit un retorn, una restauració de la realitat, on aquesta deixa de ser un conjunt de possibilitats, deixa de ser mera idealitat, $i$ esdevé, en aquesta curvatura que describiem, real per a cada subjecte. Aquest procés tí un simil en el pensament cartesià, per qui, a la sisena Meditació, s'escau efectivament una recuperació de la realitat puix que ja no li cal témer que "siguin falses les coses que els sentits representen", ni li cal "dubtar de la veritat de les coses" i pot, per tant, "rebutjar per hiperbòlics i ridiculs tots els dubtes del passat". El mètode és per tant un recurs iniciàtic en la pràctica filosòfica de pensar el món, que, una vegada consumat, n'assegura l'existència. I, en consequència, la recuperació cartesiania del món val d'una vegada per totes. Així, Descartes acaba hipostatitzant el món, diria K'ierkegaard, puix que s'estructura a la mercè d'un saber pretesament universal, quelcom inadmissible per Kierkegaard. La realitat cartesiana acaba essent mera "Realitet", o sia, mera dada fisico-matemàtica, sotmesa al capritx operatiu filosòfic: acaba essent un resultat del procés i no el procés mateix d'actualització que Kierkegaard accentúa. La realitat cartesiana, i amb ella, el realem en la filosofia, no és res més que un constructe, un artifici fantàstics.

(2) Pel que fa al concepte kierkegaardià de reflexió, al moment pròpiament del pensar filosòfic, hem vist que implica un moment objectivament del món, un distanciament. El dubte, és, segons Climacus "una determínació de la reflexió" (Pap. IV BI, pl. 127). Fóra possible llegir el dubte cartesià en aquests termes $i$, de fet, Descartes en parla com un rompiment amb el món, com una reclussió en el nucli de la seva subjectivitat que indentificarà con la res cogirans. Adhuc si cal entendre aquesta ruptura de forma merament metodològica, Kierkegaard considera aquest espasme escèptic una ficció, el qual oposa al tarannà escèptic de l'Antiguitat, on el 
dubte "no és vençut mitjançant la via epistemològica, la via del coneixement". L'aillaınent del món que el filòsof modern es dicta a si mateix per mor del pensar filosòlic no solament és impossible, sinò inadmissible car, en ell, "el filòsof ha de ser indiferent i cruel" (Pap. IV B! pl. 128): és una quimera, no solament des del punt de vista epistemològic, sinò també des del punt de vista pragmàtic. La praxi filosòfica, en definitiva, no pot entendre l'escisió amb la praxi senso lato, puix que la tê com a objecte i hi està limitada. El rigor en el pensar filosòtic, que Descartes garantia amb el dubte, té un deute amb l'existència, per dir-ho kierkegaardianament, que no pot ésser negligit si hom no vol córrer el risc de la ingenuitat metodológica o de la contradicció performativa.

(3) Finalment, Kierkegaard acusaria Descartes d'haver dut a terme una tasca de reflexió "desinteressada" (Pap. IV BI pl. 148), o sia, amb l'únic objectiu d'estructurar, organitzar i aniquilosar la realitat entre teorema $i$ teorema. La praxi a què convida el mètode cartesià és merament de caire epistemologic i objectivant $i$, aixi, no satisfa el dubte com a "determinació de la voluntat" sinó solament com a "necessitat del coneixement" (Pap. IV B5, 6). El moment de la doble refexió o d'exigència d'actualització de les possibilitats que és la realitat és absent. O sia, el filòsof modern no se sent involucrat per la negació que du a terme de la realitat $i$ hi roman al marge. I, d'aquesta manera, superada la negació, la realitat és merament "re-descoberta", "re-coneguda" en termes abstractes. Kierkegaard troba a faltar l'accent pragmàtic en el mètode cartesià. 